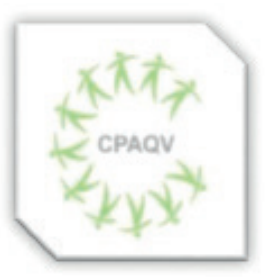

ISSN: 2178-7514

Vol. 14| No. 1| Ano 2022
ARTIGO DE REVISÃO

\section{ENSINO E APRENDIZAGEM FUTEBOL SOCIETY PARA CRIANÇAS EM INICIAÇÃO 4 E 7 ANOS}

\section{Teaching and learning Soccer Society for children 4-7 years old.}

\title{
RESUMO
}

Com aumento na procura de se fazer alguma atividade física os pais de crianças de idade 04 e 07 anos vem buscando escolinhas de futebol para prática do esporte mais popular no Brasil, o futebol propõe as crianças uma condição excelente de se exercita pela fácil aceitação de ela ter uma bola para prática dos exercícios. É de suma importância a realização de atividades físicas e uma alimentação saudável, a saude física e mental promovendo interação com outras crianças e prevenção de doenças diabetes, obesidade infantil.As escolinhas de futebol classificam essa categoria de FUTBABY aonde as crianças se iniciam ao futebol sem ter nenhuma técnica e habilidade, os exercícios aplicados são voltados para coordenação motora, percepção de espaço e lúdico.A prática de atividade física regular, e uma alimentação saudável, traz um controle de doenças e prevenção, principalmente as crianças, que doenças como obesidade diabetes tem aumento significado alto nos últimos anos com a prática do futebol a uma melhora no estilo de vida das crianças trazendo grandes benefícios na sua saúde.

Palavras-chave: Capacidade motora infantil.Capacidade intelectual.Atividade física. Educação física.

\begin{abstract}
With an increase in the demand for physical activity, parents of children aged 04 and 07 years old have been looking for soccer schools to practice the most popular sport in Brazil, soccer offers children an excellent condition to exercise because of its easy acceptance. have a ball to practice the exercises. It is extremely important to carry out physical activities and healthy eating, physical and mental health promoting interaction with other children and preventing diabetes and childhood obesity. The soccer schools classify this category of FUTBABY where children start soccer without any technique and skill, the exercises applied are aimed at motor coordination, space perception and playfulness. The practice of regular physical activity, and healthy eating, brings disease control and prevention, especially for children, that diseases such as obesity and diabetes have increased significantly in recent years with the practice of football and an improvement in children's lifestyle bringing great benefits to your health.
\end{abstract}

Keywords: Children's motor skills. Intellectual capacity. Physical activity.

Autor de correspondência

Ricardo Pablo Passos - rppasso@gmail.com

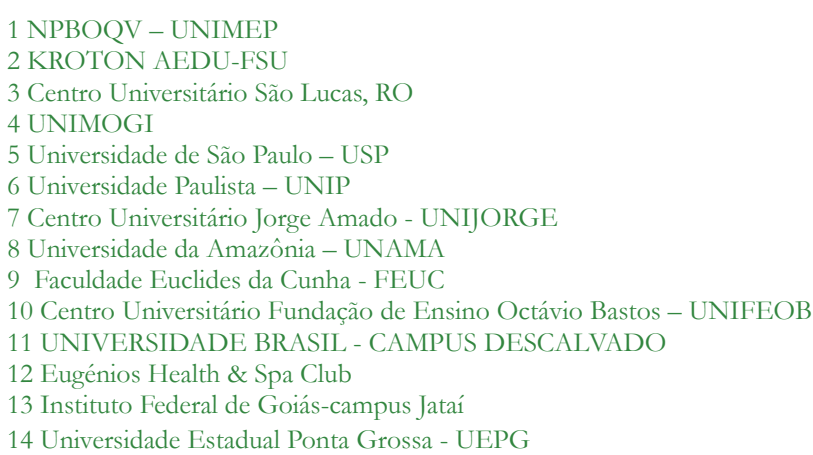

3 Centro Universitário São Lucas, RO

4 UNIMOG

6 Universidade Paulista - UNIP

7 Centro Universitário Jorge Amado - UNIJORGE

8 Universidade da Amazônia - UNAMA

9 Faculdade Euclides da Cunha - FEUC

11 UNIVERSIDADE BRASIL - CAMPUS DESCALVADO

13 Instituto Federal de Goiás-campus Jatai

14 Universidade Estadual Ponta Grossa - UEPG 


\section{INTRODUÇÃO}

Com aumento na procura de se fazer alguma atividade física os pais de crianças de idade 04 e 07 anos vem buscando escolinhas de futebol para prática do esporte mais popular no Brasil, o futebol propõe as crianças uma condição excelente de se exercita pela fácil aceitação de ela ter uma bola para prática dos exercícios.

É de suma importância a realização de atividades físicas e uma alimentação saudável, a saúde física e mental promovendo interação com outras crianças e prevenção de doenças diabetes, obesidade infantil .

As escolinhas de futebol classificam essa categoria de FUTBABY aonde as crianças se iniciam ao futebol sem ter nenhuma técnica e habilidade, os exercícios aplicados são voltados para coordenação motora, percepção de espaço e lúdico.

A prática de atividade física regular, e uma alimentação saudável,traz um controle de doenças e prevenção, principalmente as crianças, que doenças como obesidade diabetes temaumento significado alto nos últimos anos com a prática do futebol a uma melhora no estilo de vida das crianças trazendo grandes benefícios na sua saúde.

E a questão norteadora é: qual a importância de se praticar futebol na fase primaria na adolescência, e seus benefícios a saúde.
Como objetivo geral foi traçado avaliar como o treinamento influência no desenvolvimento físico e técnico e na qualidade de vida das crianças. E como objetivos específicos tem se: avaliar a capacidade motora e intelectual da criança, pesquisar sobre metodologia em que melhore as capacidades físicas e biologias da criança e discutir e avaliar os benefícios que se dá pela prática do esporte na fase primaria da criança

Com aumento e crescimento das cidades vem também os problemas causados pala vida moderna aonde as crianças perdem mais espaços em seu lazer e esporte e se mantém em uma condição mais presas dentro de sua casa.É muito importante que busquem alternativas para minimizar possíveis doenças que afeta direta ou indiretamente sistema imunológico de biológico das crianças.

O futebol tem uma influência de melhorar a capacidade força, flexibilidade resistência,justamente melhorando, esse aspecto funcional que irão diminuir nas criança e conseqüentemente, acredita se com a capacidade dessas duas funções tem grande influência significativa na qualidade de vida das crianças.

Todo processo de metodologia deve ser compreendido como o processo eficaz frente a construção do processo de conhecimento crítico e assertivo enquanto acadêmico e profissional em formação. E para que isso seja construído de forma eficaz deve se 
indagar todos os limites e questionamentos acerca do presente estudo. Em virtude de todos os questionamentos que são levantados e construído sé preciso que a pesquisa seja construída em cima de uma aptidão acadêmica que ocorre sempre em função da busca de artigos e livros que contemplem o estudo1.

Assim sendo, para que toda a pesquisa seja realizada em cima de um conhecimento crítico e sistemático a delimitação do tema se fez presente para que todos os agentes da pesquisa fossem devidamente qualificados. Sendo assim, para que este trabalho conseguisse obter respostas, optou se por uma revisão de literatura, pois ela é capaz que qualificar todos os agentes que circundam o cotidiano humano2.

Sendo assim, é importante entender que este tipo de abordagem foi escolhido em virtude da possibilidade de se aprofundar no estudo e permitir que ocorra uma profunda investigação das questões que se correlacionam ao que é estudado. Promovendo uma grande valorização do tema, mesmo com essa valorização as facetas individuais são preservadas e questionadas, para que dessa forma novas ideias de descobertas do tema sejam realizadas3.

Para que este estudo se qualifique de maneira eficaz foram pesquisados artigos que compreendem desde o ano de 2015 até o ano de 2020. As buscas foram realizadas nas seguintes bases de dados: Medley,Scielo e Lilacs. E os descritores utilizados são: capacidade motora infantil, capacidade intelectual, atividade física, educação física.

\section{EXPECTATIVAS FRENTE AO} DESENVOLVIMENTO INFANTIL

As práticas físicas são descritas ao longo dos anos como uma ferramenta de interação social e principalmente no auxílio da prevenção do sedentarismo e de todas as conseqüências do mesmo. Dessa forma, quando a criança, de quatro a sete anos, é inserida da prática do futsal ela consegue estabelecer relações positivas as quais irão permanecer por toda vida.

A Educação Física escolar é a disciplina que os alunos em geral mais gostam, pois a associam a um momento de lazer e recreação. Contudo, ela é uma aula tão importante como qualquer outra, rica em conhecimentos que poderão trazer aos educados diversos benefícios em seu cotidiano, despertando o prazer de aprender, de potencializar a capacidade de criar e recriar situações de aprendizagem.

Além de ampliar a capacidade de comunicação do educando, ela se torna significativamente importante para a nossa promoção de saúde, conhecimento e bem-estar, bem como a prática do esporte na escola como iniciação pode proporcionar o descobrimento de um atleta de alto nível. É durante a infância que a criança tem o primeiro contato com pessoas que não são seus familiares, seja na vizinhança ou na escola. 
A socialização é uma das principais vantagens da prática da Educação Física escolar, pois é durante essas atividades que o aluno tem a oportunidade de se sentir aceito pelo grupo, desenvolver a autoconfiança e as habilidades motoras. A longo prazo, a Educação Física tende a levar o aluno a descobrir motivos e sentidos nas práticas corporais, favorecer o desenvolvimento de atitudes positivas, levar à aprendizagem de comportamentos adequados à sua prática, levar ao conhecimento, compreensão e análise de seu intelecto os dados científicos e filosóficos relacionados à cultura corporal de movimento, dirigir sua vontade e sua emoção para a prática e a apreciação do corpo em movimento.

$\mathrm{Na}$ sociedade contemporânea, o pilar educação pelo esporte é uma das vias poderosas e privilegiadas para desenvolver o potencial de crianças e adolescentes. Esta educação voltada para o esporte onde quer que seja praticada implica em espelhar os objetivos educacionais inerentes aos princípios de cidadania, de diversidade, de inclusão social e de democracia. Enfim, o esporte educacional implica na formação de valores, hábitos e atitudes.

Entende-se que o esporte aliado à educação torna-se uma poderosa arma na área da proteção social e no resgate de crianças e adolescentes em situações de risco, pois esta ferramenta irá manter estes atores ocupados com atividades prazerosas, preenchendo o seu tempo de forma útil e agradável, não os deixando ociosos nas ruas.
As atividades físicas e desportivas têm especial importância, pois de um modo em geral oferecem uma gama de ações destinadas a aplicar construtivamente o tempo livre. Estudos nas mais diferentes modalidades apontam para os benefícios da iniciação esportiva, bem como para os riscos, quando os sujeitos se encontram afastados de uma base pedagógica.

A prática do esporte vai muito além das disputas dentro dos estádios e ginásios. Por isso cada vez mais cresce a sua importância como ferramenta de inclusão social. Ao aliar Esporte e Educação de qualidade é possível permitir que crianças e adolescentes se sintam participantes da sociedade, além de possibilitar que eles desenvolvam habilidades de concentração e coordenação motora, fundamentais para o desenvolvimento físico, psicológico e para o processo educacional.

A sociedade globalizada convive com um permanente conflito no universo da relação capital-trabalho. Esse processo apresenta nítidas repercussões nos mais diversas setores gerando um desequilíbrio econômico e social no mundo contemporâneo. Vivemos nesse contexto de diversidade, relatividade e de pluralidade de valores.

Estar em sintonia com as necessidades e avanços, problemas, enfim com a realidade das pessoas, da comunidade, dos grupos sociais, da nação e do mundo, faz-nos ancorar nesta perspectiva contextual. O futebol, por sua vez dentro desta perspectiva, desde sua implantação 
no Brasil, se organizou não somente de acordo com o contexto social e cultural vigente, mas também econômico, visando desta forma o mercado da bola.

Portanto, observou se ao longo dos últimos anos uma ótima crescente quando se analisa a prática das atividades relacionadas ao futsal. Ele é o promotor de interações sociais e prevenção do adoecimento. Portanto dessa maneira é interessante que as crianças sejam estimuladas a tal prática.

\section{A IMPORTÂNCIA DO FUTSAL}

O desenvolvimento motor se baseia em estudar as ações, comportamentos e mudanças desde o nascimento, o decorrer da vida até a morte. Sendo assim, o desenvolvimento motor é de grande importância para a manutenção da vida e também na melhora das habilidades motoras básicas.

Conforme explicado acima o desenvolvimento motor é o processo pelo qual cada ser humano passa, que pode ser aperfeiçoado através de pratica motora, e do crescimento maturacional. Este processo necessita de analise por fases e períodos, cabendo conhecimento em cada etapa do desenvolvimento para um melhor resultado dentro do que necessita4.

Sem um profundo conhecimento dos aspectos do desenvolvimento do comportamento humano, os educadores somente podem supor as técnicas educacionais e os procedimentos de intervenção apropriados. os educadores que se baseiam no modo desenvolvimentista em seu ensino incorporam experiências de aprendizado que são apropriados não somente às idades cronológicas, mas também, de maneira mais importante, aos níveis de desenvolvimento dos indivíduos que estão sendo ensinados5.

A iniciação esportiva é a fase que a criança começa a aprender práticas esportivas de forma organizada e orientada. Compreender a fase que a criança se encontra é fundamental para aplicação de atividades corretas e fundamentadas. A faixa etária de 6 a 12 anos, é uma etapa que processo de desenvolvimento esportivo mais abrangente e excelente para melhora6.

É interessante, aliás, aplicar conteúdos de trabalhem o desenvolvimento de habilidades que integram sistema de controle motor. A utilização na pratica atividades lúdicas para que tenha maior entretenimento do público alvo, é uma das formas para que desenvolva aspectos importantes na aprendizagem e trazendo assim uma evolução apropriada7.

Crianças de 6 a 10 anos é fundamental nessa fase que tenha atividades com repetições organizadas, sendo com procedimentos que motivem e aprimore práticas e comportamentos para que levem para a vida. Para a faixa etária de 11 e 12 anos, existe a capacidade de aprender sendo assim essencial trabalhar para que não se 
torne a aquisição de movimento automatizada de forma errada4.

Cada fase necessita de uma dedicação, assim se faz da responsabilidade do conhecimento passado. A melhor maneira de compreender esse processo é considerar que na faixa etária existe a necessidade de desenvolver aspectos motores fundamentais para o desenvolvimento e aprendizagem. Não se trata de apenas aplicar conteúdos, mas que estes conteúdos contenham informações e conhecimentos objetivos6.

Iniciação Esportiva Universal é uma alternativa pedagógica importante para a faixa etária entre 4-6 anos e 11-12 anos. Nestas faixas etárias, o jogo deve ser um elemento didáticopedagógico que deverá ser oferecido, conforme as características evolutivas da criança, especialmente no que refere à maturidade, evolução psicológica e cognitivo-social5.

Em virtude do aumento do repertorio motor faz com auxilie na melhora do desenvolvimento motor, assim a complexidade dos movimentos básicos traz junto os benefícios em relação a aprendizagem motora. Essa, porém, é uma tarefa que precisa de mudanças significativas nas atividades. Vê-se, pois, que a partir desta situação poderemos ver resultados na melhora 7.

O esporte é um fenômeno cada vez mais presente na nossa sociedade, principalmente na vida das crianças, devido à influência de seus pais. Observamos um elevado crescimento em nível de modalidades esportivas e, de ambientes que proporcionam a prática deste, por conseqüência percebemos o aumento no número de crianças iniciadas no processo de ensino aprendizagem no desporto e, este tem sido significativo8.

O esporte vem de inúmeras formas seduzir a criança, seja por clubes, academias, projetos esportivos, ou escolas. Contudo, a iniciação esportiva, ao ser feita respeitando a criança em sua totalidade, ou seja, considerando suas limitações, desenvolvimento físico, psíquico e social, proporcionará diversos benefícios ao praticante?.

Entretanto, quando se negligencia estes fatores na infância, e este sujeito é especializado precocemente, como um adulto em miniatura, sob pressões psicológicas para realizar a técnica com perfeição e eficiência, impedindo-a de ter prazer e compreensão do esporte, basicamente não propicia a criança uma seqüência didática que permita a mesma absorver o esporte em sua formação integral colaborando no desenvolvimento motor, físico, cognitivo, afetivo e social10.

A iniciação esportiva engloba uma sistematização de ensino mais ampliada que se inicia aos sete anos de idade e termina por volta dos quatorze anos. A iniciação esportiva é caracterizada por um processo cronológico no transcurso do qual o indivíduo tem experiências a partir de regras de uma determinada modalidade esportiva ou simplesmente quando 
a criança tem contato com a aprendizagem de forma especifica a vários esportes, tendo como objetivo principal dar continuidade ao desenvolvimento do sujeito em sua totalidade, não o submetendo a competições regulares11.

Desta forma podemos inferir que existe uma diferença entre iniciação esportiva e especialização precoce, onde a iniciação deve proporcionar diversos estímulos relacionados à ambiente e movimentos e, a especialização precoce ser a unilateralização dos movimentos, isto é, o refinamento das ações em uma determinada posição e/ou estilo dentro de uma modalidade esportiva, antes da fase pubertária8.

Em consonância com a idéia acima, uma habilidade esportiva bem desenvolvida, não garante a mesma habilidade em outras, por isso devemos também estimular à prática de outras atividades antes de especializá-lo, pois, a frustração, daquele que é especializado precocemente, por ter que se adequar a uma nova posição ou modalidade esportiva no futuro, poderá levá-lo a interrupção da carreira9.

Existem dois estágios de movimentos rudimentares, o primeiro é o estágio de inibição e o segundo é o estágio de pré-controle sendo o primeiro começa a partir do desenvolvimento do córtex que começa a inibir vários reflexos e dão início a movimentos voluntários embora voluntários, mas ainda descontrolados e grosseiros, já o segundo estágio as crianças aprendem a adquirir seu equilíbrio, manipular objetos, e locomover-se pelo espaço físico com um bom grau de controle sendo esse processo de ganho explicável pelo processo de maturação11.

A terceira fase como fase de movimentos fundamentais, este período apresenta grandes descobertas motoras devido a criança conseguir combinar vários tipos de habilidades, ou seja, pular, correr, arremessar, apanhar, andar com firmeza, e equilibrar-se em um pé só. Existem três estágios que sub-classificam os movimentos fundamentais que são o inicial, elementar e maduro, sendo o inicial marcado por uso exagerado e coordenação deficitária9.

\section{A IMPORTANCIA DO FUTSAL E AS DEMANDAS INFANTIS}

Educação Física tem um papel fundamental para a escola, pela possibilidade de proporcionar aos alunos uma diversidade de experiências através de situações nas quais elas possam criar, inventar, descobrir movimentos novos, reelaborar conceitos e idéias sobre o movimento e suas ações, descobrindo seus próprios limites.

A Educação Física Escolar é um dos meios pelo qual a educação pode acontecer, mas se estiver voltada para o aluno como um todo e se inserida dentro do planejamento escolar, buscando conteúdos e atividades de significância para o seu desenvolvimento. A busca pela autonomia pedagógica que se 
vislumbrou nas últimas décadas vem por legitimar a importância da Educação Física como componente curricular escolar12.

Assim, tem-se hoje como área de conhecimento e objetivos a cultura corporal de movimento, no qual se busca a linguagem corporal como elemento central das práticas. Os conteúdos da Educação Física têm em suas concepções pedagógicas legitimar a área enquanto princípios e finalidades, na busca de uma autonomia pedagógica, e com isso, vem ao encontro de questões em relação ao papel da escola e da prática docente que auxilia no planejamento adequado desses conteúdos.

Os conteúdos curriculares da Educação Física Escolar é uma ferramenta pedagógica voltada à orientação dos planos de estudos de atividades físicas e práticas corporais, estabelecendo relações equilibradas e construtivas com os outros, reconhecendo e respeitando o nível de conhecimento, as habilidades físicas e os limites de desempenho dos alunos13.

Os conteúdos da Educação Física Escolar estão divididos em dois grupos. O primeiro está organizado com base nas práticas tradicionais da Educação Física como: esporte, ginástica, jogo motor, lutas, práticas corporais expressivas, práticas corporais junto à natureza e atividades aquáticas14.

O segundo conjunto está organizado com base no estudo das representações sociais que constituem a cultura de movimento e afetam a educação dos corpos de um modo geral. Assim, entende-se que os conteúdos fazem parte de um conjunto de conhecimento no qual abrange dimensões: conceitual, que se relaciona com "o que" se quer aprender/ conhecer; procedimental, a qual abrange as vivências práticas do conteúdo a ser estudado; e atitudinal, que trata do comportamento do aluno12.

Ultimamente, tem-se demonstrado significativamente grande interesse por projetos e trabalhos acadêmicos, envolvendo metodologia que mais se identificam com o universo infantil: os jogos e brincadeiras. Destaca-se que alguns pesquisadores Vygotsky, Piaget, Kishimoto, Sisto, entre outros estudiosos, enfatizam a função e importância do lúdico na formação da criança12.

Ao longo da história, foram surgindo idéias divergentes em relação aos jogos: para uns, representava a possibilidade de fazer a criança gastar mais energia e dar um pouco de tranqüilidade; para outros, representava a possibilidade de preparar a criança para a vida, despertando o ponto de equilíbrio. Os colégios, embora tradicionais, ainda mantinham a disputa dos jogos 8 .

Acredita-se que através do uso dos jogos, possa-se difundir e estimular nos educados, o seu desenvolvimento lógico, assim fazendo relações, concluindo e concretizando de forma agradável e interessante, o conteúdo o qual estão estudando. No contexto 
educacional nem toda atividade lúdica pode ser concebida como recurso pedagógico, a ação pedagógica intencional do professor deve refletir na organização do espaço, na seleção dos brinquedos e na interação com as crianças, nesse sentido.

Rigorosidade metódica é uma das exigências do ensinar, pois busca proporcionar ao aluno um aprendizado crítico aproximandoos das teorias que levam ao conhecimento de modo a instigar-lhes a curiosidade e a não aceitação de que, aquele conhecimento é inquestionável. Os jogos são instrumentos eficazes para o desenvolvimento do ser humano. O professor deve estar atento também à idade e auxiliar a criança na utilização do brinquedo até que esteja apta a brincar sozinha. O professor deve também participar das brincadeiras, demonstrando prazer e estimulando-as a participar.

O professor deve elaborar algumas atividades que serão exemplificadas objetivando reproduzir a essência das competições, conquanto saibamos, como já destaca por diversos autores, que por mais que objetivemos reproduzi-las, determinadas situações jamais serão idênticas as adotadas pelos adversários, pois o futsal tem a invariável individualidade dos jogadores, suas particularidades e diferentes criações que, naturalmente, irão distingui-los, porém, acredita-se que os jogos e treinamento devam se aproximar ao máximo as situações de jogos encontradas nas competições.
A maioria das ações motoras durante uma partida de futsal acontece sem a posse de bola. Os jogadores profissionais de futsal ficam 17\% do tempo de jogo parado, 40\% andando, $35 \%$ correndo em baixa intensidade e $8 \%$ em alta intensidade. Para a realização de todas as demandas de uma partida de futsal, os alunos/ jogadores, devem ter perfil fisiológico que correspondas as necessidades do jogo13.

Nas últimas décadas isso tem mudado muito, tornando cada vez mais competitivas e exigentes as condições atléticas dos participantes, é importante que tenhamos conhecimento das capacidades motoras necessárias para a prática da modalidade, traçando um perfil fisiológico dos alunos. Ao se falar em capacidades motoras dentro das aulas de educação física, deve-se primeiramente levar em consideração que cada aluno é um ser individual, além dos fatores socioeconômicos que podem influenciar no desenvolvimento da criança dentro da escola, é importante entender que também existe o fator genético como determinante em muitas praticas bem ou malsucedidas9.

Em uma aula de educação física bem elaborada e aplicada de forma correta pelo professor, pode influenciar no desenvolvimento integral do aluno, visto que não se trata apenas das capacidades motoras que estará sendo trabalhada. Os movimentos básicos como andar, correr, saltar; noções espaço-temporal, velocidade, flexibilidade, agilidade, lateralidade e 
equilíbrio; além de contribuir para uma melhor socialização entre as crianças, contribuindo para um melhor conhecimento de si e de todos que fazem parte daquele grupo de estudante6.

Dessa forma, o aluno irá refletir sobre suas limitações e as limitações dos colegas, entendendo, aceitando e respeitando as qualidades e os possíveis defeitos de si mesmo e dos demais colegas. Nesse sentido, a integração coletiva que um jogo esportivo, em nosso caso, o futsal, proporciona vai além da quadra, sendo relevante na formação da conduta moral que os alunos irão assumir fora da escola, dentro de um seio social14.

Entender o corpo e as limitações dos alunos dá ao professor a possibilidade de equiparar suas práticas de forma a encontrar meios de agregar a todos nas aulas sem que haja distinção de tamanho, idade ou sexo, dessa forma o professor conseguirá atender a todos de forma igualitária.

\section{CONSIDERAÇÕES FINAIS}

Atualmente a sociedade vive em um circuito muito competitivo; no universo esportivo não é diferente. Vários veículos de comunicação demonstram que o esporte ocupa gradativamente um espaço cada vez maior nesse cenário, principalmente entre as crianças. Para entender esse fenômeno, alguns fatores devem ser considerados devidos à contribuição no início da prática esportiva, ocorrida cada vez mais cedo.
Como exemplos, têm-se o grande número de eventos esportivos em nível mundial, adoração aos ídolos sempre em evidência, pressão familiar, como também uma tentativa de ascensão social. Todavia, além da criatividade em relação a essa tendência que se afirmar, devem-se buscar alternativas para combater a cultura do rendimento esportivo a todo custo. Inicialmente, deve-se entender que a iniciação esportiva é o momento de primeiro contato da criança com prática regular com o esporte. Nesta fase as crianças estão em pleno desenvolvimento das capacidades físicas. Por esse motivo não deve esquecer que a referida fase é genuína, vista como um processo que desenvolve em longo prazo.

\section{REFERÊNCIAS}

1. MARTINS, Heloísa Helena Teixeira Silva. Metodologia qualitativa de pesquisa. Educação e Pesquisa, São Paulo, v.30, n.2, p. 287-298, maio/ago. 2016.

2. GODOY, Arilda Schimidth. Pesquisa qualitativa: tipos fundamentais. Revista de Administração de Empresas, Rio de Janeiro, v. 35, n.3, p. 20-29. mai./ jun. 2015.

3. OLIVEIRA, Maria Fernanda. Metodologia científica: um manual para a realização de pesquisas em administração. 2011. 73f. Trabalho de Conclusão de Curso (Especialização)- Faculdade de Administração, Universidade Federal de Goiás, 2020.

4. ARENA, Simone Sangres. Crescimento e desenvolvimento com qualidade de vida. $1^{\text {a }}$ ed. São Paulo: Phorte, 2016.

5. GREGÓRIO, Karla Mello; SILVA, Thaise da. $\mathrm{X}$ especialização esportiva precoce: quando iniciar estas práticas? Horizontes, Revista de Educação, v. 2, n. 3, 2017.

6. HAYWOOD, Katleen; GETCHELL, Nancy. Desenvolvimento motor ao longo da vida. $\sigma^{\mathrm{a}}$ ed. Porto Alegre: ARTMED, 2016.

7. TANI, Go; BASSO, Luciano; CORRÊE, Umberto Cesar. O ensino do esporte para crianças e jovens: considerações sobre uma fase do processo de desenvolvimento motor esquecida. Revista Brasileira de Educação Física e Esporte, v. 26, n. 2, p. 339-350, 2018. 8. AUGUSTI, Marcelo. Treinamento de endurance 
para crianças e adolescentes. Universidade Federal de São Paulo. Revista Digital, Buenos Aires, Año 7. No 37 Junio de 2021.

9. GALLAHUE, David L.; OZMUN, Jhon C. Compreendendo o desenvolvimento motor: bebês, crianças, adolescentes e adultos. São Paulo, Phorte, 2015. 10. MACHADO, Afonso Antonio (Org.). Especialização esportiva precoce: perspectivas atuais da psicologia do esporte. Jundiaí, SP: Fontoura, 2018.

11. PERRONI, Milena Gomes. Estudo de casos: lesões musculoesqueléticas em atletas de voleibol em alto rendimento. Universidade Federal do Rio Grande do Sul. Escola de Educação Física. Dissertação de mestrado (Programa de PósGraduação em Ciências do Movimento Humano) Rio Grande do Sul. 2017.

12. ANDRÉ, Marli. Pesquisa em Educação: Buscando rigor e qualidade. Cadernos de Pesquisa, n. 113, p. jul./2021.

13. DARIDO, Suraya. Os conteúdos da Educação Física Escolar: Influências, Tendências, Dificuldades e Possibilidades. In. Perspectivas em Educação física Escolar, Niterói, v. 2, n.1 (suplemento), 2021.

14. MARINHO, Alcyane; SCHWARTZ, Gisele. Atividade de Aventura como conteúdo da educação física: reflexões sobre seu valor educativo. In. Revista Digital - Buenos Aires - Año 10- no88 - Setiembre de 2015.

OBSERVAÇÃO: Os autores declaram não existir conflitos de interesse de qualquer natureza. 